АСТВАЦАТУРОВА Майя Арташесовна - доктор политических наук, профессор; директор Научнообразовательного центра политических и этнополитических исследований Пятигорского государственного университета (357532, Россия, Ставропольский край, г. Пятигорск, ул. Калинина, 9; maya.astv@gmail.com)

ВОРОНЦОВ Сергей Алексеевич - доктор юридических наук, профессор кафедры процессуального права Российской академии народного хозяйства и государственной службы при Президенте РФ (119571, Россия, г. Москва, пр-кт Вернадского, 82, cmp. 1; raven_serg@таil.ru)

ПОНЕДЕЛКОВ Александр Васильевич - доктор политических наук, профессор; заведующий кафедрой политологии и этнополитики Российской академии народного хозяйства и государственной службы при Президенте РФ (119571, Россия, г. Москва, пр-кт Вернадского, 82, cmp. 1; ponedelkov@ skags.ru); заслуженный деятель науки РФ

ИГНАТОВА Татьяна Владимировна - доктор экономических наук, профессор, заведующий кафедрой кафедры экономической теории и предпринимательства Российской академии народного хозяйства и народного хозяйства и государственной службы при Президенте РФ (119571, Россия, г. Москва, пр-кт Вернадского, 82, стр ; есtheоry@игіu.ranера.ru)

\title{
УПРОЧЕНИЕ ГРАЖДАНСКОГО ЕДИНСТВА В ЭТНОПОЛИТИЧЕСКОМ КОНТЕКСТЕ ЮГА РОССИИ (политико-управленческие идеи
} и экспертное мнение)

Аннотация. Статья посвящена принципам и направлениям (политико-властным и организационноуправленческим) упрочения единства российской гражданской нации при актуализации конкуренции этнической и гражданской идентичностей. Обобщаются мнения экспертов некоторых субъектов Юга России по поводу полиэтничности и поликонфессиональности, причин этнических конфликтов, эффективности реализации национальной политики и деятельности национально-культурных организаций. Ключевые слова: российская идентичность, гражданское единство, национальный вопрос, национальная политика, власть и управление в сфере межэтнических отношений, этнический конфликт, национально-культурное самоопределение

3 адачи, стоящие перед современным российским обществом, обозначенные в политико-управленческом контексте федерального уровня, прежде всего в послании президента РФ В.В. Путина Федеральному собранию РФ и в его инаугурационной речи, актуализируют гражданскую консолидацию российского общества, прочность гражданского единства россиян ${ }^{1}$. В этой связи дискуссии об основах такого единства, об интегративных традиционных и новационных ценностях, о соотношении национального (как гражданского) и этнического (как собственно этнического) в феноменологическом и институциональном планах не только существуют, но и имеют высокую практическую значимость.

Современный российский научно-исследовательский контекст красноречиво свидетельствует, во-первых, о давности серьезных исследований этнического и национального, во-вторых, о непреходящей актуальности и креативности научного поиска в отношении этнического и национального в контексте политико-властных процессов [Тишков 2011]. Наряду с впечатляющими фундаментальными исследованиями этничности и гражданственности, которые заняли достойное место в мировой этнологии, этносоциологии, этнополитологии и этноконфликтологии, в современной российской науке осуществля-

\footnotetext{
1 Послание Президента РФ В.В. Путина Федеральному Собранию РФ. 1 марта 2018 г. Доступ: http:// www.kremlin.ru/events/president/news/56957
} 
ются текущие и актуальные (неотложные) исследования этнической идентичности и гражданской идентичности, гражданского патриотизма [Абрамов 2016]. Штатный регламент таких исследований катализируется потребностями реального национального (гражданского) и этнического пространства, а также и реальными внутри- и внешнеполитическими обстоятельствами.

Симптоматичным стало оживление экспертных усилий, а также общественных дискуссий и информационных сюжетов, посвященных соотношению этнического и национального в российском обществе, в связи с идеей принятия федерального закона о российской нации, которая была озвучена на заседании Совета при Президенте РФ по межнациональным отношениям ${ }^{1}$. Острый дискурс, который последовал за данным предложением, можно оценивать как продуктивный, т.к. он выявил большой спектр мнений по данному поводу и иллюстрировал настроения граждан, национально-культурных ассоциаций, политической элиты (в т.ч. и этнократических кругов), а также экспертного сообщества. Фактически вслед за заседанием Совета при Президенте РФ по межнациональным отношениям состоялся блиц-аудит общественного мнения по проблеме единства россиян как гражданской полиэтничной нации в содержательном и терминологическом отражении этого понятия. Дискурс вновь подтвердил тезис о том, что этнополитика - это искусство только возможного и только в конкретном политическом времени и политическом пространстве. Среди множества аргументов как «за», так и «против» принятия закона о российской гражданской нации выделились однозначные тезисы, которые подтверждают а) необходимость дальнейшего упрочения гражданского единства россиян для решения масштабных внутри- и внешнеполитических задач; б) опасность противопоставления таких категорий (и реально действующих коллективных субъектов), как российская гражданская нация и многонациональный народ России; в) целесообразность оптимального сочетания национальных (государственно-гражданских общероссийских) и этнических (этноязыковых, этнокультурных, этнотерриториальных) интересов индивидов, народов и этнических групп; г) полиэтничность как креативный ресурс прогресса российского общества и социальной мощи Российского государства; д) эффективность российского федерализма при сочетании разных принципов образования субъектов (административно-территориальный и национально-государственный); е) целесообразность этнокультурной модели гражданского общества, которая сложилась на основе этнических интересов и межкультурного взаимодействия.

Комплексная проблема единства российской гражданской нации при сохранении этнокультурной самобытности россиян нашла отражение во многих политико-доктринальных документах, начало которым было положено статьей президента РФ В.В. Путина «Россия: национальный вопрос». Президент РФ обозначил принципы современного понимания национального вопроса, значение традиционных духовных основ гражданского патриотизма 2 . После распада СССР, после «этнического ренессанса», межэтнических противоречий и этнических и этнополитических конфликтов, попыток сецессии, состоявшихся в стране (прежде всего, на Северном Кавказе), сфера межэтнического взаимодействия, этнополитического структурирования и национально-государственного и национально-культурного самоопределения находится под

1 Заседание Совета при Президенте РФ по межнациональным отношениям в Астрахани. 31 октября 2016 г. Доступ: http://www.kremlin.ru/events/president/news/53173; Заседание Совета при Президенте РФ по межнациональным отношениям в Йошкар-Оле. 20 июля 2017 г. Доступ: http://www.kremlin.ru/ events/president/news/55109

2 Путин В.В. Россия: национальный вопрос. - Независимая газета. 2012. 23 янв. 
пристальным вниманием политической элиты РФ [Национальный вопрос... 2013; Михайлов, Абдулатипов 2016].

Этнокультурные и этнополитические процессы современного российского общества актуализированы Стратегией государственной национальной политики Российской Федерации на период до 2025 года, утвержденной указом Президента РФ в 2012 г. ${ }^{1}$ C 2017 г. разработана и внедрена Государственная программа РФ «Реализация государственной национальной политики»².

Важнейшей проблемой политики, власти и управления является проблема соединения многообразия страны при высоком уровне этнокультурной дифференциации отдельных общностей и регионов с упрочением гражданской нации и обеспечением гражданского единства [Зорин, Аствацатурова 2016]. Этнополитический тренд 2016-2018 гг. показал, что в РФ продолжают проявляться некоторые риски и угрозы, наносящие ущерб единству российской гражданской нации, что может рассматриваться как угроза национальной безопасности Российской Федерации [Воронцов, Локота, Понеделков 2017: 45-46]. В числе угроз и рисков следует также выделить проявления террористической и экстремистской активности, распространение радикальных мировоззрений и групп, проявления национализма и ксенофобии, неурегулированность канализированных этнических конфликтов и противоречий, реполитизацию деятельности некоторых национально-культурных организаций. Периодически отмечается акцентирование национальных вопросов (в т.ч. и в конфликтных формах) в связи с земельно-территориальным переустройством, сужением пространства национальных языков, проведением реформы МСУ и попытками образования «этнических территорий». Также типичны такие конфликтогенные ситуации, как обустройство мигрантов и соотечественников; формирование этнократических и этноклановых систем власти и управления; включение религиозных норм (мировоззренческих и обрядовых) в политико-управленческие практики; рекрутирование молодежи в радикальные сообщества и ячейки; конкуренция российского светского законодательства с нормами религиозного права; распространение нетрадиционных верований и деноминаций (неоязычество, родноверство, «новые религии», «народные религии» и др.).

Осмысление современных реалий и тенденций власти, политики и управления в контексте соотношения этнического и национального (гражданского) свидетельствует о том, что:

- проблемы межэтнических отношений в общественном мнении и общественных ожиданиях россиян ушли на второй и третий план на фоне озабоченности по поводу материального состояния, экономического положения, занятости, уверенности в завтрашнем дне;

- прецедент Крыма и внешняя политика руководства РФ в целом послужили упрочению патриотических настроений и сплочению российского общества вокруг внешнеполитической доктрины РФ и действий главы государства;

- выборы президента РФ в марте 2018 г. стали свидетельством гражданского единства и гражданской активности россиян, которые, несмотря на очевидные трудности (экономические, финансовые, социальные), проявили высокий уровень доверия первому лицу государства;

- информационный «язык вражды» в российских СМИ существенно ослаб при усилении гражданского интегративного информационно-коммуникативного метатекста.

\footnotetext{
1 Указ Президента РФ от 19 декабря 2012 г. № 1666 «О стратегии государственной национальной политики Российской Федерации на период до 2025 года». Доступ: http://президент.pф/news/17165

2 Распоряжение Правительства РФ от 28 апреля 2016 г. № 805-р «Реализация государственной национальной политики». Доступ: https://government.consultant.ru/files/3709496
} 
Вместе с тем отдельные противоречия - бытовые, территориальные, земельные, политико-управленческие - одномоментно этнизируются и трансформируются в межэтнические противоречия. Отчетливое этнополитическое содержание имеют общественные и политико-властные противоречия, связанные с урегулированием прошлых конфликтов и с полной (социальной) реабилитацией репрессированных и перемещенных народов или этнических групп. Ксенофобия, национализм и мигрантофобия часто проявляются в интернетпространстве, в социальных сетях и блогах, а также на сайтах экстремистского содержания. Проблемное содержание имеет ситуация с преподаванием национальных языков как родных и государственных в соответствующих республиках, равно и противоречивые интерпретации получают дискуссии о возможности и целесообразности использования религиозной атрибутики в одежде учащихся как в государственных, так и муниципальных образовательных учреждениях и др.

Указанные проблемы свидетельствуют о необходимости постоянного совершенствования властных и политико-управленческих технологий оптимизации этнического и национального (гражданского) компонентов в социальной и политической жизни российского общества [Участие органов... 2016]. При этом свою роль играют мониторинговые исследования, которые выявляют содержание установок, мнений, ожиданий и опасений граждан в сфере этнической идентичности, этнокультурного ассоциирования и межкультурной коммуникации.

Так, на Юге России (в Южном и Северо-Кавказском федеральных округах - ЮФО и СКФО) систематически ведутся мониторинговые исследования, проводятся экспертные оценки качества межэтнических отношений, «отложенных» и реальных конфликтов, а также составляются прогнозы их возможной актуализации. В ряде субъектов РФ (ЮФО И СКФО) по инициативе Южно-Российского института управления - филиала Российской академии народного хозяйства и государственной службы при Президенте РФ (ЮРИУ РАНХиГС) проведен экспертный опрос по выявлению потенциала гражданского единства при сохранении этнокультурного и конфессионального многообразия сообществ Юга России ${ }^{1}$. Проблемное поле исследования обусловливалось проблемами России как страны, в которой исторически сложилось полиэтничное, многокультурное и поликонфессиональное общество и которая является многосоставным федеративным государством с множеством регионов, отличающихся этнодемографическими, этносоциальными параметрами [Гражданское единство... 2018].

Гипотеза исследования предполагала трактовку гражданского единства как необходимое условие развития российского общества и национальной безопасности Российского государства, а этнокультурное и конфессиональное многообразие - не как фактор дифференциации и разделения, а как фактор консолидации в соответствии с положениями Стратегии государственной националь-

\footnotetext{
1 Социологическое исследование (экспертный опрос - по 60 экспертов в каждом субъекте) проводилось лабораторией проблем повышения эффективности государственного и муниципального управления ЮРИУ РАНХиГС в период с февраля по апрель 2018 г. на территории следующих субъектов РФ: Ростовская обл., Краснодарский край, Ставропольский край, Республика Северная Осетия-Алания, Кабардино-Балкарская Республика, Карачаево-Черкесская Республика, Чеченская Республика. В каждом субъекте РФ по единому инструментарию опрашивались 60 экспертов: 1-я группа - 10 работников органов государственной власти; 2-я группа - 10 работников органов местного управления; 3-я группа - 10 представителей общественных религиозных организаций, активистов религиозных общин; 4-я группа - 10 представителей национально-культурных организаций и автономий, этнических советов; 5-я группа - 10 работников СМИ, журналистов, блоггеров; 6-я группа - 10 работников вузов и НИИ (ученых, преподавателей). Возраст опрашиваемых: от 21 года до 67 лет; половое соотношение: 35 мужчин, 25 женщин.
} 
ной политики Российской Федерации на период до 2025 года. Соответственно, политические, управленческие, организационные и самоорганизационные усилия власти и общества должны быть направлены на устранение причин и факторов возможного конфликта внутри иерархии идентичностей при усилении гражданской идентичности, гражданского патриотизма.

Гипотеза исследования учитывала, что а) продолжаются процессы модернизации политической системы Российского государства; б) осуществляется дальнейшая демократизация всех сторон жизни российской нации, однако при сохранении традиционных историко-культурных и общественно-политических ценностей; в) отмечаются противоречия между модернизацией и традиционализацией, между либерально-демократической и консервативно-охранительной патронажной моделями политического процесса и политического управления.

В ходе исследования выявлялось мнение экспертов о состоянии межэтнических отношений и этнополитических процессов в субъектах их проживания, а также мнение о содержании и соотношении этнической, региональной и российской гражданской идентичностей, о функционале национально-культурных организаций, о содержании и формах управления в сфере межэтнических отношений, о причинах этнических конфликтов и др.

Анализ результатов опроса показал, что мнения экспертов, в данном случае из Ростовской обл., Ставропольского и Краснодарского краев, во многом совпадают в силу схожих историко-культурных, социальных и инфраструктурных характеристик выделенных субъектов РФ. Эксперты из названных регионов на вопрос, как они понимают этноконфессиональное самоопределение, прежде всего из вариантов ответов выделили такой, как «возможность свободного выбора религии и веры, либо выбора нерелигиозного мировоззрения»: $37 \%$ ответов - Ростовская обл.; 63\% - Ставропольский край; 100\% - Краснодарский край.

Большинство экспертов (от 70 до 100\% ответов) считают регионы их проживания многонациональными и при этом оценивают полиэтничность и поликонфессиональность как благоприятный фактор развития и взаимодействия жителей (от 50 до 100\% ответов). В то же время эксперты из этих регионов отмечают, что полиэтничность и поликонфессиональность при их объективности являются конфликтогенными факторами общественных отношений (до $75 \%$ ответов). Среди недостатков в реализации государственной национальной политики эксперты выделяют такие причины, как а) недостаточный авторитет и популярность решений органов власти и МСУ среди населения (63\% Ростовская обл., 53\% - Ставропольский край); б) отдаленность органов власти и МСУ от насущных проблем народов, диаспор, этнических групп (64\% - Ростовская обл., 33\% - Ставропольский край, 100\% - Краснодарский край). Показательны ответы на вопрос о необходимости реализации национальнокультурного самоопределения в виде общественных организаций и автономий. Эксперты отмечают, что такие формы необходимы и отвечают интересам граждан: $37 \%$ - Ростовская обл.; 41\% - Ставропольский край, 68\% - Краснодарский край. Также эксперты подчеркивают важность сотрудничества органов власти и управления с национально-культурными организациями: $47 \%$ - Ростовская обл.; 70\% - Ставропольский край, 100\% - Краснодарский край. Также эксперты в большинстве своем считают, что лидеры национально-культурных и религиозных организаций призваны пропагандировать не только традиционные ценностей народов (Ростовская обл., Ставропольский край, Краснодарский край - 23\%, 68\%, $100 \%$ соответственно), но и гражданское единство российской нации для консолидации граждан России (Ростовская обл., Ставропольский и Краснодарский края $-77 \%, 26 \%, 22 \%$ соответственно). 
Эксперты из Ростовской обл., Ставропольского, Краснодарского краев дали оценку форм и методов профилактики национализма и ксенофобии на Юге России по 5-балльной шкале: Ростовская обл. - до 4,8 баллов, Ставропольский край - до 3,9 баллов, Краснодарский край - до 4,9 баллов. Среди направлений, в которых необходимо дальнейшее совершенствование политики и управления в сфере межэтнических и этноконфессиональных отношений, эксперты выделили уважение и понимание групповых интересов народов в решении национальных вопросов в каждом конкретном регионе и на местах - 52\% (Ростовская обл.); расширение профилактических мероприятий и акций, предотвращающих угрозы терроризма, экстремизма, национализма - 60\% (Ставропольский край); нейтрализацию последствий прошлых конфликтов, террористических актов на базе патриотизма и гражданской консолидации северокавказского сообщества - 100\% (Краснодарский край).

Изложенное позволяет утверждать, что укрепление единства российской гражданской нации при сохранении этнокультурной самобытности россиян -важная задача органов государственного управления, причем задача весьма сложная, т.к. принципы гражданственности часто противоречат принципу беспрекословного подчинения граждан власти. Решение данной задачи представляется достижимым при постепенном расширении институциональных рамок невмешательства, благодаря чему государственная политика может стать одним из главных институциональных механизмов повышения гражданской активности и упрочения гражданской идентичности жителей России, последовательного и системного включения их в политическую жизнь на местном, региональном и федеральном уровнях.

Четкое институциональное разграничение зоны ответственности государства и гражданского общества является необходимым условием упрочения гражданской идентичности. В данном случае у организаций, ориентированных на воспроизводство и реализацию гражданского мировоззрения и гражданской идентичности, расширится институциональное пространство, в котором недостатки, имеющиеся в работе государственных органов, и нарушение ими прав граждан будут подвергаться системной и объективной критике.

Правомерен вывод, что гражданская идентичность в региональной социальной и политической среде представляет собой поле определенных противоречий и многих перспективных усилий как власти, так и граждан. Это актуализирует масштабный потенциал гражданской идентичности как важнейшего политико-управленческого проекта, осуществление которого в современных условиях может обеспечить реализацию человеческого потенциала общества и привести его в соответствие с задачами инновационного развития.

\section{Список литературы}

Абрамов А.В. 2016. Российский патриотизм: история и современность. М.: Изд-во ИИУ МГОУ. 184 с.

Воронцов С.А., Локота О.В., Понеделков А.В. 2017. Основы национальной безопасности Российской Федерации: учебное пособие. Ростов н/Д: Изд-во ЮРИУ РАНХиГС. 320 с.

Гражданское единство, этнокультурное и конфессиональное многообразие как ценностные основания и факторы консолидации российского общества: информационно-аналитические материалы научно-практической конференции с международным участием. 2018. Ростов н/Д: Изд-во РАНХиГС. 80 с.

Зорин В.Ю., Аствацатурова М.А. 2016. Стратегия государственной национальной политики Российской Федерации (три года спустя). Исследования по прикладной и неотложной этнологии. М.: ИЭА РАН. Вып. 253. 41 с. 
Михайлов В.А., Абдулатипов Р.Г. 2016. Россия в ХХІ веке: общенациональный ответ на национальный вопрос. - М.: МИЦ «Этносоциум».

Национальный вопрос в российской общественно-политической жмизи. Материал к слушаниям на тему «Национальный вопрос в общественно-политической жизни России» (под ред. М.В. Романова, В.В Степанова). 2013. М.: Общественная палата. 168 с.

Тишков В. 2011. Федеральная власть и законодательный ресурс этнокультурного развития. - Вестник российской нации. Спецвыпуск 2008-2016 (№ 51). C. $102-110$.

Участие органов государственной власти, местного самоуправления и институтов гражданского общества в реализации государственной национальной, миграционной и языковой политики Российской Федерации в Северо-Кавказском федеральном округе: экспертный доклад (рец. Б.В. Аксюмов). 2016. М.-ПятигорскСтаврополь: Изд-во ПГУ. 126 с.

AStVATSATUROVA Maya Artashesovna, Dr.Sci. (Pol.Sci.), Professor; Director of the Scientific and Educational Center for Political and Ethnopolitical Studies, Pyatigorsk State University (9 Kalinina St, Pyatigorsk, Stavropol'sky Region, Russia, 357532; maya.astv@gmail.com)

VORONTSOV Sergei Alekseevich, Dr.Sci. (Legal), Professor of the Chair of Procedural Law, Russian Presidential Academy of National Economy and Public Administration (bld. 1, 82 Vernadskogo Ave, Moscow, Russia, 119571; raven_ serg@mail.ru)

PONEDELKOV Aleksandr Vasil'evich, Dr.Sci. (Pol.Sci.), Professor; Head of the Chair of Political Science and Ethnopolitics, Russian Presidential Academy of National Economy and Public Administration (bld. 1, 82 Vernadskogo Ave, Moscow, Russia, 119571; ponedelkov@skags.ru); Honored Scientist of Russia

IGNATOVA Tat'yana Vladimirovna, Dr.Sci. (Econ.), Head of the Chair of Economic Theory and Entrepreneurship, Russian Presidential Academy of National Economy and Public Administration (bld. 1, 82 Vernadskogo Ave, Moscow, Russia,119571; ectheory@uriu.ranepa.ru)

\section{STRENGTHENING OF CIVIL UNITY IN THE ETHNO- POLITIC CONTEXT OF THE SOUTH OF RUSSIA (political and managerial ideas and expert opinion)}

\footnotetext{
Abstract. The article is devoted to the principles and directions (politico-imperious and organizational-managerial) of strengthening unity of the Russian civic nation with the actualization of the competition of ethnic and civic identities. The authors summarize the opinions of experts from some subjects of the South Russia on the polyethnicity and polyconfessionality, the causes of ethnic conflicts, the effectiveness of the implementation of national policy and the activities of national cultural organizations.
}

Keywords: Russian identity, civil unity, national issue, national policy, power and governance in the sphere of interethnic relations, ethnic conflict, national and cultural self-determination 